\title{
O LUGAR DO REGIONAL NA INDÚSTRIA DO PETRÓLEO
}

\author{
Rosélia Périssé Da Silva Piquet
}

R E S U M O O presente texto tem o propósito de discutir uma questão candente do debate energético da atualidade: um país seria abençoado por dispor de ricas reservas de petróleo e gás ou as fartas rendas provenientes de sua exploração produziriam uma espécie de "maldição" por limitarem a expansão de outros setores produtivos? A avaliação dos impactos dessa induistria é complexa, por existirem profundas distinçôes entre os processos de mudança que é capaz de provocar no plano nacional ou nas áreas em que se localiza. O texto é centrado na análise das fases de exploração e produção, onde ocorrem os maiores investimentos e se registram os mais significativos efeitos multiplicadores dessa indústria, tendo como referência o caso brasileiro. Existindo ainda no Brasil a peculiaridade das principais ocorrências serem na plataforma continental marítima, com marcada concentração da produção na Bacia de Campos, os impactos regionais da indústria são analisados tomando-se o caso da região Norte Fluminense como base empirica de referência.

P A L A V R A S - C H A V E Indístria de petróleo; investimentos petroliferos; impactos regionais; Norte Fluminense; efeitos multiplicadores.

\section{INTRODUÇÃO}

$\mathrm{O}$ crescimento de qualquer economia tem como um dos seus mais relevantes pilares a segurança do abastecimento energético e, consequentemente, a diversificação das fontes de suprimento de energia torna-se uma questão estratégica no processo de planejamento dos países, envolvendo ações em diferentes áreas: econômica, tecnológica, ambiental, geopolítica e social. Como insumo básico incorporado à totalidade dos produtos e serviços a energia desempenha papel importante na esfera distributiva entre setores produtivos e regiōes. Em função de sua capilaridade no interior da estrutura produtiva seus preços têm um impacto significativo nos índices de preço em geral. Portanto, dispor de energia barata proveniente de fontes diversificadas, além de garantir segurança, representa um fator determinante na competição capitalista, definindo muitas vezes os ganhadores ou perdedores da concorrência internacional.

A situação energética do Brasil sempre foi privilegiada pelo leque de recursos disponíveis, tanto fósseis quanto renováveis, sendo a produção de petróleo e gás apenas um item de sua agenda energética. Dada a variedade de bens e serviços demandados pela indústria petrolífera stricto sensu seus desdobramentos se fazem presentes, em todo o País, em importante gama de setores industriais e tem determinado o desenvolvimento de centros de pesquisa tecnológica de ponta e a demanda por mão de obra qualificada. A rede de gasodutos que vem sendo ampliada de modo acelerado facilitará o processo de descentralização da produção industrial nacional, assim como a recente retomada dos investimentos no refino garantirá o beneficiamento do óleo nacional, transformando-o em derivados de maior valor agregado. 
Sendo esta atividade fundamental e estratégica para a soberania de qualquer Estado Nacional e capaz de gerar rupturas drásticas no plano internacional, seus aspectos geopolíticos, econômicos e tecnológicos são os mais estudados e divulgados. Em contrapartida, as áreas produtoras são vistas frequentemente como simples territórios de extração de riqueza, com relevância secundária.

A ambiguidade desta atividade é perturbadora: de um lado, se desenvolve quase de forma isolada nas localidades onde se localiza mais conectada ao mercado nacional e internacional; de outro, funciona como motor propulsor de riqueza, não só por meio da geração de empresas e empregos diretamente vinculados ao setor, mas também por via das compensaçôes financeiras que distribui às administrações públicas onde se implanta.

Esses pontos serão discutidos a seguir em dois eixos analíticos. No primeiro são apresentados os argumentos sobre o papel que a indústria do petróleo desempenha no desenvolvimento, sendo indicados os efeitos multiplicadores desse setor na economia brasileira. No segundo, são discutidas as implicaçôes regionais dessa atividade, tendo como referência empírica a região norte fluminense.

\section{A INDÚSTRIA PETROLÍFERA NO PROCESSO DE DESENVOLVIMENTO ECONÔMICO E SEU DESEMPENHO NO BRASIL: UMA SÍNTESE}

A indústria do petróleo, embora classificada como extrativa mineral, é especial, pois as características físico-químicas do petróleo na natureza exigem, para sua extração e produção, atividades de grande complexidade tecnológica, vasta pluralidade de tecnologias empregadas nas fases de sondagem e perfuração assim como extensa base multidisciplinar de conhecimento. Sua capacidade de gerar efeitos multiplicadores na economia de um dado país será, contudo, em função do grau de complexidade produtiva e econômica desse país, uma vez que, da jazida ao consumidor final, a exploração e a produção de petróleo e de seus derivados exigem um sistema industrial estruturado por diferentes segmentos de atividades industriais. Se o país dispuser apenas de um parque industrial incipiente, os efeitos multiplicadores da indústria petrolífera ocorrerão no exterior, em países cujas matrizes industriais tenham condiçôes de atender a essa demanda.

Para melhor compreensão das relações entre a indústria petrolífera e o processo de desenvolvimento, apresentam-se a seguir os traços marcantes dos segmentos integrantes da cadeia produtiva do petróleo e de seus derivados.

Por ser indústria complexa e de risco, suas diversas etapas são desenvolvidas por empresas de porte diversificado que operam em estruturas de mercado diferenciadas. Nesse competitivo mundo empresarial, o papel central é exercido pelas chamadas petroleiras (oil companies), que constituem um poderoso, seleto e pequeno grupo de empresas tais como a Shell, a Exxon e a Petrobras. Essas empresas detêm o capital e contratam serviços, como os de sísmica, de perfuração e de produção, de outras empresas altamente especializadas, que por sua vez também operam em oligopólios internacionais, dado o nível de sofisticação tecnológica exigido em suas operações.

As oportunidades de as pequenas e médias empresas participarem desse mundo tecnologicamente complexo também existem, pois é composto de uma miríade de produtos e serviços demandados que vão desde equipamentos e peças de alta tecnologia até os de confecção relativamente simples, passando por serviços de baixa qualificação e pelos de 
difícil importação. Desse modo, geralmente ocorre uma divisão de mercado em que as tarefas mais sofisticadas e mais rentáveis permanecem nas mãos das empresas transnacionais, enquanto os serviços e equipamentos de baixo conteúdo tecnológico são encomendados a empresas menores, de âmbito nacional ou local. Nas fases de prospecção e desenvolvimento da produção - quando os poços produtores são perfurados e as plataformas e demais equipamentos, instalados -, é que se concentra o percentual mais significativo de investimentos. As escalas e as especificidades dos materiais e serviços necessários são tantas, que raros países podem oferecer, competitivamente, $100 \%$ dos bens e serviços. O Brasil, assim como os Estados Unidos, a Noruega e a Inglaterra encontra-se entre os países que detêm grande produção de petróleo e grande participação dos fornecedores locais ${ }^{1}$.

O bom desempenho brasileiro se deve ao fato de que a produção de petróleo só veio a ocorrer de forma significativa em meados do século passado, quando o País já dispunha de um parque industrial de grande porte e diversificado, com elevado consumo de combustíveis, embora atendido pelas importações de óleo e derivados. Além disso, a exploração e a produção desse recurso se processaram de modo particular no Brasil, pois houve a garantia de que as reservas seriam de propriedade da União, e o pioneirismo exigido pela exploração na plataforma continental marítima gerou internamente especializado saber técnico de alta qualificação nessa área.

Uma nova etapa da história da indústria petrolífera no País tem início em novembro de 2007, quando a Petrobras anuncia que testes confirmaram a existência de uma megajazida de petróleo na Bacia de Santos na camada pré-sal, com potencial de elevar em até $40 \%$ a extração de petróleo do País. Dois meses após o anúncio dessa reserva (de Tupi), novamente a Petrobras veio a público comunicar a descoberta de uma grande jazida de gás natural, também na camada pré-sal, em águas de profundidade de $5.250 \mathrm{~m}$ e a 290 quilômetros da costa. A descoberta de uma nova província petrolífera na camada pré-sal na costa brasileira é fruto de estudos e pesquisas que começaram bem antes do anúncio feito em 2007, pois já em 2001 tivera início o maior programa de sísmica 3-D até então realizado pela empresa e em 2004 fora perfurado o primeiro poço da área do pré-sal onde foi encontrada uma acumulação de gás condensado e de óleo leve a uma profundidade de $7.600 \mathrm{~m}$. A partir de então, as descobertas se sucedem em ritmo crescente e em novembro de 2008, foi concluída a perfuração de dois novos poços no litoral do Espírito Santo. Em maio de 2009, teve início o refino do primeiro óleo do pré-sal da Bacia de Santos.

Não se limitam às reservas do pré-sal as perspectivas promissoras do setor no País. A continuidade dos estudos sísmicos em terra e na costa do Nordeste apresentou resultados positivos. Em novembro de 2010, a Petrobras anuncia a descoberta de uma reserva de petróleo leve e de gás no município de Tefé, AM. A descoberta se revestiu de grande importância, pois além de existir petróleo e não apenas gás, como na maioria das descobertas na região amazônica, a reserva está a apenas $35 \mathrm{~km}$ da província petrolífera de Urucu, no município de Coari, onde a Petrobras já produz gás natural. A província de Urucu, hoje a maior reserva provada de gás do País, tem um destacado papel no suprimento energético do Amazonas. Um gasoduto de $660 \mathrm{~km}$ entre Urucu-Coari-Manaus abastece as usinas termoelétricas de: Manauara, Tambaqui, Jacaqui, Aparecida, Mauá, Cristiano Rocha e Ponta Negra. Esse gasoduto foi a obra de dutos no País com maior percentual de uso de mão de obra local, 70\%, com 8,9 mil trabalhadores atuando diretamente na construção, e com a geração de cerca de 26,7 mil empregos indiretos. De todo o material utilizado na obra, 95\% foi produzido no Brasil, sendo o percentual de máquinas e equipamentos de $85 \%$.
1 Sobre esse ponto ver RAPPEL, Eduardo, 2011.

2 Disponivel em: <http:// www.petrobras.com.br/pt/ noticias/gasoduto-urucu-coari-manaus-mais-energia-para-o-brasil>. Acesso em: 11 ago. 2012. 
No mesmo sentido e pela primeira vez, em Sergipe é encontrado petróleo em águas profundas, a $57 \mathrm{~km}$ da costa o que caracteriza uma nova fronteira exploratória, uma vez que até então a produção petrolífera de Sergipe se concentrava em águas rasas e em terra. A descoberta é considerada importante porque as características geológicas da região são semelhantes às da Bacia de Campos e abre perspectiva para a expansão da produção de petróleo em grande escala no Nordeste.

Essa nova e promissora etapa do setor petrolífero brasileiro vem proporcionando elevados efeitos multiplicadores e até mesmo mudanças estruturais na economia brasileira, pois de acordo com a Agência de Informaçôes de Energia dos Estados Unidos (US Energy Information Administration), o Brasil é a principal fronteira para a expansão da produção de petróleo no mundo, no horizonte até 2030, conforme indicam os dados do Gráfico 1.

Gráfico 1 - Projeção de aumento na produção de petróleo entre 2008 e 2030

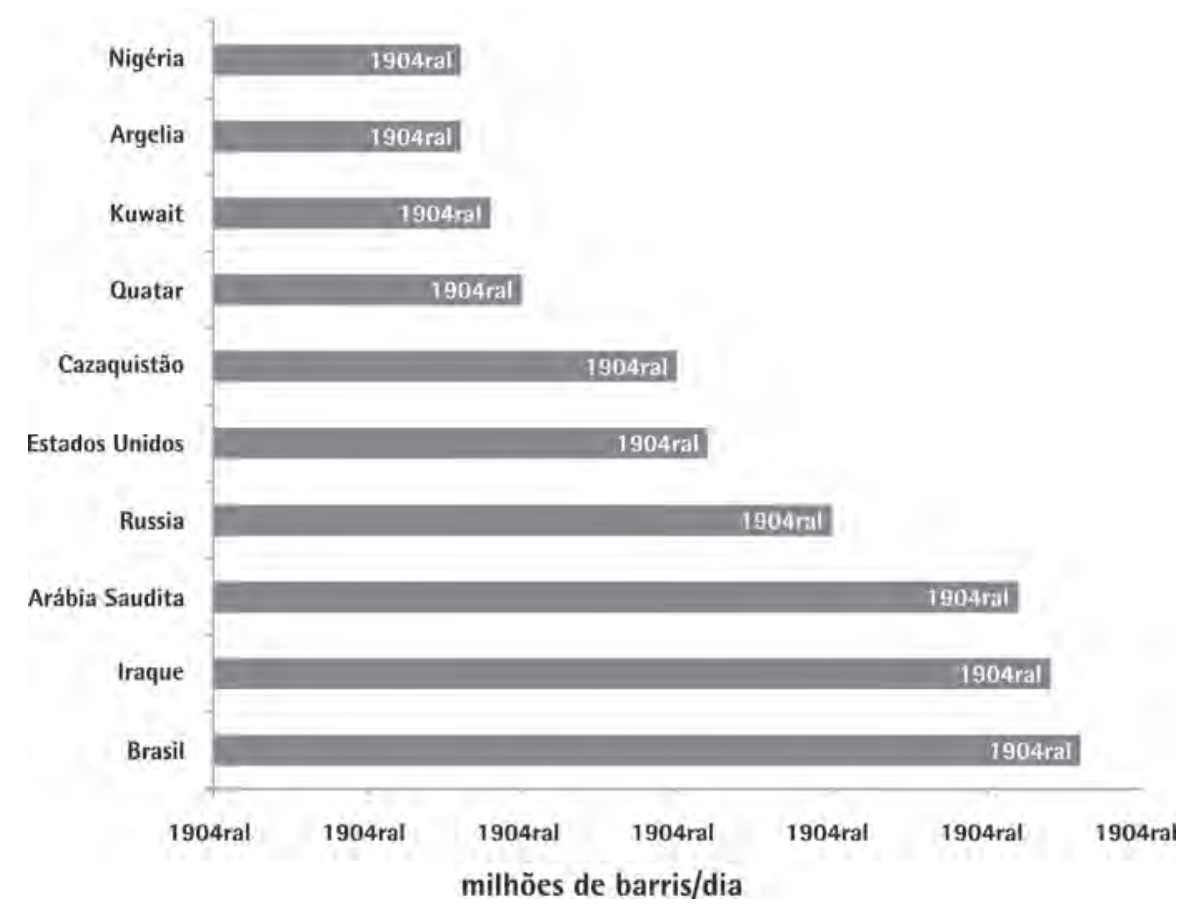

Fonte: US Unergy Information Administration, apud Sant'Anna (2010).

As projeções do Plano Decenal de Energia brasileiro para 2010-2019 são ainda mais ousadas, uma vez que preveem forte crescimento da produção de petróleo para o período, que passará dos 2,2 milhões de barris por dia, em 2010, para 5,1 milhões de barris diários, em 2019, quando então o País se tornará grande exportador de petróleo.

Com base em estudo do BNDES, as perspectivas de investimentos nos principais setores na indústria brasileira, entre 2011-2014, são de R \$ 614 bilhões, conforme dados da Tabela 1, dos quais $\mathrm{R} \$ 378$ bilhōes $(61,5 \%)$ no setor de petróleo e gás, sendo que as inversões na província do pré-sal respondem por $\mathrm{R} \$ 45$ bilhóes do total mapeado. 
Tabela 1 - Investimentos mapeados na indústria, 2011-2014

\begin{tabular}{|l|c|c|}
\hline Setores & R\$ Bilhões & $\%$ \\
\hline Petróleo e gás & 378 & 61,5 \\
\hline Extrativa mineral & 62 & 10,2 \\
\hline Siderurgia & 33 & 5,3 \\
\hline Química & 40 & 6,5 \\
\hline Papel e celulose & 28 & 4,5 \\
\hline Veículos & 33 & 5,4 \\
\hline Eletroeletrônica & 29 & 4,8 \\
\hline Têxtil e confecções & 12 & 1,8 \\
\hline Indústria & 614 & 100 \\
\hline
\end{tabular}

Fonte: BNDES/GT do Investimento, apud Puga e Borça Jr. (2011)

Os dados apresentados na Tabela 2 indicam que os investimentos estão concentrados nos segmentos de exploração e produção e são realizados majoritariamente pela Petrobras. Do montante previsto de $\mathrm{R} \$ 378$ bilhões, a Petrobras será responsável por $80 \%$ de todo o volume a ser investido. A maioria dos investimentos (60\%) será em exploração e produção, em razão, em grande parte, das dificuldades tecnológicas e logísticas para sua operacionalização.

Tabela 2 - Perspectivas do investimento em petróleo e gás (2011-2014)

\begin{tabular}{|c|c|c|c|c|c|}
\hline \multicolumn{3}{|c|}{ Distribuiçãao por empresas } & \multicolumn{3}{|c|}{ Distribuição por segmentos } \\
\hline & R\$ bilhōes & $\%$ & & R \$ bilhōes & $\%$ \\
\hline Petrobras & 303 & 80 & Exploração e produção & 229 & 60 \\
\hline Demais empresas & 75 & 20 & $\begin{array}{l}\text { Refino, transporte e } \\
\text { comercialização }\end{array}$ & 112 & 30 \\
\hline & & & Gás e energia & 25 & 7 \\
\hline & & & Outros* & 11 & 3 \\
\hline Total & 378 & 100 & & 377 & 100 \\
\hline
\end{tabular}

* Considera petroquímica, distribuição, combustível e corporativos

Fonte: IBP, apud Sant'Anna (2010).

Como os investimentos realizados pela indústria do petróleo e gás têm importante papel de mobilizar uma ampla cadeia de fornecedores de bens e serviços, a estimativa (com base na matriz de insumo-produto) é que esses investimentos resultarão em forte efeito multiplicador nesses setores econômicos, sendo que do total dos investimentos previstos para o setor, 55\%, cerca de $\mathrm{R} \$ 205$ bilhôes, resultarão em encomendas nacionais. $\mathrm{O}$ setor 
de máquinas e equipamentos será de longe o maior beneficiado, tendo em vista que haverá uma demanda doméstica direta adicional de R $\$ 190$ bilhōes e uma demanda indireta de $\mathrm{R} \$ 43$ bilhôes. A magnitude dos investimentos impóe relevantes desafios para a cadeia de suprimentos que deverá apresentar padrão tecnológico compatível e custos competitivos com os do mercado internacional.

Tabela 3 - Impacto total dos investimentos previstos para o período 2011-2014 sobre a produção nacional (em R \$ Bilhões)

\begin{tabular}{|l|c|c|c|}
\hline & Efeito direto & Efeito indireto & Total \\
\hline Máquinas e equipamentos & 190 & 43 & 233 \\
\hline Metalurgia & 2 & 29 & 31 \\
\hline Demais setores produtivos & 3 & 61 & 64 \\
\hline Comércio & 0 & 17 & 17 \\
\hline Serviços & 10 & 52 & 62 \\
\hline Total & 205 & 202 & 407 \\
\hline
\end{tabular}

Fonte: Sant'Anna (2010).

Conforme já indicado anteriormente, a pesquisa tecnológica voltada à indústria petrolífera foi uma das alavancas mais importantes para que o País caminhasse para a autossuficiência em petróleo e seus derivados. O Centro de Pesquisa e Desenvolvimento Leopoldo Américo Miguez de Mello (Cenpes), pioneiro e o mais importante centro de pesquisa do setor implantado pela Petrobras em área da Universidade Federal do Rio de Janeiro, na Ilha do Fundão, foi o sustentáculo da exploração em águas profundas e ultra profundas

3 Sobre esse ponto ver $\mathrm{FF}$ LHO, E. C. "O papel da pesquisa nacional na exploração e explotação petrolífera da margem continental da Bacia de Campos". In: PIQUET, R. (Org.). Petróleo, Royalties e Região. Rio de Janeiro: Garamond, 2003.

4 A apresentação detalhada do perfil científico e tecnológico dos principais centros de pesquisa vinculados ao setor petrolífero está disponível em: <http://www.petrobras. com.br/pt/energia\%2De $\% 2$ Dtecnologia/tecnologia $\% 2 \mathrm{De} \% 2 \mathrm{Dpesquisa}$. Acesso em: 14 jul. 2011. na costa brasileira ${ }^{3}$.

Com o contínuo crescimento das descobertas no setor, a empresa passou a fomentar uma rede de mais de 70 laboratórios em universidades, distribuídos por 19 estados da Federação, que visam desenvolver pesquisas indispensáveis à exploração do pré-sal e também oferecer condições ao avanço da ampliação do conteúdo nacional nas encomendas da empresa. Como principal polo de pesquisa do setor, o Rio de Janeiro reúne além, do Cenpes, os importantes laboratórios da Coordenação de Pós-Graduação em Engenharia (Coppe) da Universidade Federal do Rio de Janeiro.

Um dos mais significativos sinais da mudança de comportamento de grandes grupos econômicos internacionais sobre o papel que o petróleo brasileiro desempenhará no plano mundial do setor é o fato de grandes empresas internacionais estarem instalando centros de pesquisa no Rio de Janeiro. Assim, a britânica BG Group anunciou, em março de 2011, que nos próximos 10 anos pretende realizar investimentos de US\$1,5 bilhão em um centro de pesquisa tecnológica na Ilha do Fundão. Por sua vez, a General Electric, na mesma ocasião, anunciou investimentos de US\$ 550 milhões para a construção de um centro de pesquisa dedicado a petróleo e gás no mesmo local. E grandes empresas que já operam no Brasil, há anos, como é o caso da francesa Schlumberger e da norte-americana Halliburton, também estão instalando laboratórios de pesquisa no mesmo polo. ${ }^{4}$

Embora sejam promissores os dados apresentados, a magnitude dos investimentos revelou os gargalos a serem vencidos, entre os quais destacam-se a baixa capacidade/inte- 
resse das empresas nacionais de investirem em pesquisa tecnológica e a baixa qualificação da mão de obra brasileira. Assim, os equipamentos comprados dos fornecedores locais estão predominantemente limitados a itens de baixo valor agregado. Segundo a Associação Brasileira de Máquinas e Equipamentos (Abimaq), nos principais grupos de equipamentos, $37 \%$ provêm de fornecedores estrangeiros e $38 \%$ não têm similar nacional, indicando o quanto é necessário avançar para que a participação nacional seja mais significativa nos itens de maior valor agregado. Além disso, os equipamentos nacionais custam de $10 \%$ a $40 \%$ a mais que um similar importado.

A falta de qualificação de mão de obra está no topo da lista de reclamações da indústria e já é apontada pelo governo como o principal gargalo a ser vencido para atender às crescentes demandas da economia. $\mathrm{O}$ mais grave é que não se trata apenas de uma carência de preparo técnico ou especializado, esta talvez de mais fácil enfrentamento. $\mathrm{O}$ mais alarmante é que somente $25 \%$ dos brasileiros dominam a escrita, a leitura e a matemática para se expressarem e entenderem o que está à sua volta nos contextos econômico e tecnológico atuais, conforme indica pesquisa realizada pelo Instituto Paulo Montenegro sobre "Indicador de Analfabetismo Funcional", em 2009. A carência de mão de obra qualificada não se restringe ao nível técnico, pois no ensino superior, na área das engenharias, a situação é também crítica. Segundo a Associação dos Engenheiros da Petrobras, como os cursos de graduação em engenharia mecânica e naval encontravam-se esvaziados pela profunda crise que levou o setor de construção naval no País a praticamente desaparecer, há enormes dificuldades em contratar profissionais disponíveis nas áreas de engenharia de fabricação de equipamentos e montagem das plataformas.

Como o cenário da indústria naval mudou radicalmente, em função de deliberada política do governo do Presidente Lula em garantir maior participação às empresas nacionais no fornecimento ao setor petrolífero, os maiores estaleiros do País voltaram à ativa graças às encomendas para a construção de plataformas e seus módulos, de navios de apoio marítimo, de petroleiros para o transporte de óleo bruto e seus derivados. Apenas para se ter uma ideia sobre a força desse renascimento, o emprego no setor naval aumentou de 2 mil postos de trabalho no ano 2000, para 78.400 empregos diretos, em 2010 (Sinaval, 2010).

Pelo exposto, infere-se o forte poder de difusão que a indústria do petróleo e gás é capaz de exercer, bastando para tal que a estrutura produtiva do país seja diversificada o suficiente para internalizar seus efeitos multiplicadores.

\section{O LUGAR DO REGIONAL}

A indústria do petróleo deflagra dois tipos de impactos nos territórios em que se localiza: os diretamente ligados à atividade industrial e os que decorrem do recebimento das compensações financeiras.

Do ângulo estritamente econômico há sempre a possibilidade de se realizar um balanço sobre seus efeitos quanto à criação e destruição de riquezas que possa ocasionar.

O primeiro desses aspectos, a criação de riqueza, poderá ser avaliada pelo incremento bruto quanto à disponibilidade de bens e serviços no âmbito regional, diretamente decorrente do empreendimento. A nova capacidade produtiva agregada pela indústria se reflete, necessariamente, em alteraçôes nos mercados de terra urbana e rural; na maior oferta de postos de trabalho; na melhoria do sistema de comunicação e transporte da infraestrutura 
regional; nas mudanças no sistema urbano e na qualidade de vida. A destruição de riqueza se traduz em perdas de emprego em setores tradicionais da região, emigração, danos ambientais, desocupação de áreas agrícolas, processos esses que constituem o lado negativo do balanço quanto aos impactos regionais. É fácil perceber que são variáveis difíceis de serem quantificadas e mostra que um mesmo empreendimento pode ser considerado positivo ou negativo, dependendo dos critérios de avaliação.

No Brasil, a região que vem passando por transformaçōes radicais em sua estrutura produtiva é o Norte Fluminense, uma vez que cerca de $80 \%$ do petróleo e $42 \%$ do gás produzidos no Brasil são extraídos da Bacia de Campos, assim denominada em função de sua proximidade com a cidade de Campos dos Goytacazes. Tal procedimento, de adotar para uma bacia o nome de uma cidade próxima ou acidente geográfico, é internacionalmente seguido e regido pelo Código de Nomenclatura Estratigráfica. A área sedimentar dessa bacia se estende do Espírito Santo (próximo ao alto de Vitória) até ao Alto de Cabo Frio, no litoral norte do Estado do Rio de Janeiro.

Foi somente na década de 1960 com o maior domínio sobre as técnicas de exploração offshore que a Petrobras desenvolveu suas atividades de forma mais expressiva na plataforma continental e a seguir, nos anos de 1970, decide implantar uma base operacional autônoma na cidade de Macaé, contrariando as expectativas de que seria na cidade de Campos dos Goytacazes, a mais importante da região. Tal decisão vai resultar na instalação na cidade de centenas de empresas prestadoras de serviços, de padrão produtivo intensivo em capital e em tecnologia, que passam a definir uma nova paisagem econômica regional. Presença de firmas transnacionais de renomada atuação no setor petrolífero, infraestrutura logística em ampliação, empresas de serviços à produção e, ainda, comércio mais sofisticado, foram os marcos mais visíveis dessa nova paisagem econômica.

Neste caso específico, as atividades petrolíferas se inserem em uma região historicamente baseada na produção de cana-de-açúcar e na pecuária bovina, já então em franco declínio. $\mathrm{O}$ empreendimento da Petrobras provocou transformaçôes rápidas e radicais na organização do território, acarretando profundas mudanças na estrutura populacional, no emprego, na malha urbana, no quadro político e na cultura local. Os efeitos dessa mutação revelam-se particularmente desiguais entre centros urbanos, mais ou menos inseridos na nova economia regional.

Tendo como foco a cidade de Macaé, toda a região passa então a ser vista como um espaço dinâmico que oferece oportunidade de trabalho e perspectivas de ascensão social para populações de baixa renda que para aí se dirigem em intensos fluxos migratórios, fato comum na totalidade das regióes que são objeto de empreendimentos de grande porte. $\mathrm{O}$ epicentro desse processo de mudança, o município de Macaé, embora na atualidade ostente vigor econômico diretamente relacionado às atividades de extração, produção e logística do petróleo, que o situa entre os de melhor relação entre postos de trabalho e população do Estado do Rio de Janeiro, apresenta também sobrecarga nos serviços de utilidade pública, escassez de moradias e outras mazelas que uma ocupação industrial acelerada e sem planejamento acarreta nos locais em que se fixa.

A partir de 1997, com a Lei do Petróleo - que determinou o fim do monopólio estatal além de mudar o cálculo quanto ao recebimento dos royalties e participações especiais - o quadro regional mais uma vez muda, pois se deslocam para Macaé novas petroleiras que, ao lado da Petrobras, passam a operar diretamente na produção offshore. Entretanto, como sustenta a literatura acadêmica voltada à economia e ao planejamento urbano e regional, uma vez que se passou a operar com categorias locais e não mais nacionais, com 
categorias socioterritoriais e não mais técnico-fabris, faz-se necessária a compreensão das dinâmicas produtivas específicas dos territórios ou das cidades em questão. O problema-chave seria então criar condições de infraestrutura e institucionais específicas, capazes de alimentar a capacidade das pequenas e médias empresas de participar ativamente das cadeias globais de valor.

Como as atividades petrolíferas passam a representar para a economia regional ao mesmo tempo um leque de oportunidades e um conjunto de restrições, uma vez que há fortes barreiras à entrada na cadeia produtiva do setor, se observa no contexto institucional regional o crescimento das organizaçóes representativas dos interesses empresariais. Surgem não só novas associações de defesa do meio empresarial, como o Grupo de Empresas Prestadoras de Serviços do Petróleo e Afins - Geps, como novas seçōes de entidades nacionais instaladas em Macaé. Dentre estas destacam-se as sedes regionais da Organização Nacional das Indústrias do Petróleo (ONIP) e do Instituto Brasileiro do Petróleo (IBP) e, ainda, a decisão da Firjan de abrir uma nova unidade local do Senai. Essas entidades não só atuam no âmbito da capacitação e apoio às empresas locais como também qualificando pessoal. Merece destaque a criação do Instituto Macaense de Metrologia (IMMT), autarquia municipal que atende a enorme demanda de ensaios de instrumentos de medições, pois uma única plataforma de extração de petróleo pode acumular até 1.500 instrumentos que devem ser aferidos pelo menos uma vez por ano ${ }^{5}$.

Talvez a iniciativa mais importante seja, contudo, o Programa Rede Petro-BC, lançado pela Petrobras e um conjunto de instituições em fins de 2005, cujo objetivo foi o de articular as empresas locais buscando a cooperação e o aprendizado mútuo de modo a atuarem coletivamente. A estratégia adotada foi a de promover a melhoria de competitividade das pequenas e microempresas fornecedoras da cadeia. Dois programas implantados pelo Ministério de Minas e Energia em âmbito nacional, mas que vêm beneficiando diretamente Macaé são o Programa de Mobilização da Indústria Nacional de Petróleo e Gás - Prominp - que busca garantir a participação da indústria nacional de bens e serviços em bases competitivas e sustentáveis perante as concorrentes externas e o Plano Nacional de Qualificação Profissional, voltado para a formação de mão de obra especializada para o setor. As instituiçôes de ensino, tanto públicas quanto particulares, também têm ampliado a oferta de cursos voltados ao setor, principalmente, em Campos dos Goytacazes e secundariamente em Macaé, uma vez que a demanda por pessoal e serviços qualificados é extremamente elevada.

A situação muda radicalmente quando se analisa a situação dos demais municípios do Norte Fluminense. Os “impactos” que sofrem são aqueles decorrentes do recebimento dos royalties e das participações especiais que a legislação brasileira garante a todo município confrontante com poços em operação. Sem nenhum dos ônus que a indústria do petróleo causa, passam a contar com elevadas receitas advindas do setor.

Do ponto de vista conceitual o pagamento de royalties serviria para recompensar as regiões produtoras pelo aumento dos custos nos serviços básicos de educação e saúde, pela sobrecarga nos transportes, na demanda de infraestrutura, e outras mazelas urbanas, provocadas pelas atividades industriais em seu território. Assim compreendido, esse imposto pode ser interpretado como uma "indenização", e, nesse sentido, somente Macaé teria direito ao seu recebimento, pois, como visto, é o único município onde se realizam as atividades de apoio à extração de petróleo e gás. $\mathrm{O}$ recebimento de royalties também se justificaria sob outro argumento: prover os governos locais dos recursos necessários para financiar investimentos que gerem riqueza alternativa para substituir a "riqueza exaurida", ou seja, a oriunda de recursos naturais não renováveis, como é o caso do petróleo.
5 Sobre esse ponto consultar FAURÉ, Y. "Macaé: internalizar as oportunidades do petróleo e diversificar a economia municipal". In: FAURÉ, Y.; HASENCLEVER, L. (Orgs.) 0 desenvolvimento local no estado do Rio de Janeiro. Rio de Janeiro: E-Papers Serviços Editoriais, 2005. 
Em ambos os casos, pode-se questionar: mesmo quando a descoberta do óleo é na plataforma marítima (offshore) e o município e/ou cidade não funciona como apoio às operações industriais e quando nada em seu território foi exaurido, o argumento se sustentaria? Qual a justificativa para designar esses municípios de "produtores"? Só porque a legislação brasileira assim os definiu? Não seria mais adequado serem considerados como "petro-rentistas"? Na Tabela 4 são apresentados dados sobre municípios das regiōes Norte e Noroeste que retratam de modo claro e inquestionável uma desigualdade de difícil defesa. Qual a lógica econômica, social ou jurídica que sustenta uma desigualdade tão profunda entre municípios costeiros e interioranos quanto os que os dados revelam?

Tabela 4 - Royalties + participações especiais anuais em valores reais e per capita* em municípios selecionados do norte e noroeste do estado do Rio de Janeiro, 2011

\begin{tabular}{|l|c|c|c|c|}
\hline \multicolumn{1}{|c|}{ Beneficiário } & Localização & População & Valor Real & Valor per capita \\
\hline Campos dos Goytacazes & Costeira & 463.545 & $897.146 .902,95$ & $1.935,40$ \\
\hline Macaé & Costeira & 206.748 & $449.940 .924,59$ & $2.176,28$ \\
\hline Quissamã & Costeira & 20.244 & $85.583 .931,97$ & $4.227,62$ \\
\hline São José da Barra & Costeira & 32.767 & $188.401 .999,38$ & $5.749,75$ \\
\hline Conceição de Macabu & Interiorana & 21.200 & $5.597 .098,85$ & 264,01 \\
\hline São Fidélis & Interiorana & 37.553 & $6.533 .358,13$ & 173,98 \\
\hline
\end{tabular}

* Corrigidos pelo IGP-DI de julho de 2011.

Fonte: InfoRoyalties, a partir da Agência Nacional do Petróleo, IBGE e Fundação Getúlio Vargas e Censo de 2010 para população. Tabulação da autora.

Não se pretende aqui realizar uma discussão sobre as regras de repasse das rendas do petróleo e gás, mas sim apenas indicar que são frágeis e passíveis de mudança, uma vez que elaboradas em função dos diferentes interesses e momentos políticos. A rigor, nenhum poço, campo ou bacia pertence a nenhum estado ou município, pois a Constituição Federal Brasileira especifica que a plataforma continental é da União. Ou seja, não existe um direito natural de qualquer estado ou município sobre os royalties do petróleo. Esse direito foi conferido pelos governantes por meio de leis e decretos que definiram a forma de rateio dos recursos, que já foram diferentes no passado e podem ser alteradas a qualquer tempo. Cabe recordar que os royalties existem na legislação brasileira desde 1953, quando do início das atividades da Petrobras, mas eram pagos apenas para a exploração terrestre e somente em 1969 passam a incidir sobre a produção marítima, sendo então os recursos destinados exclusivamente à União. É somente com a Constituição de 1988, com a ênfase

6 Sobre o novo marco regulatório e a legislação brasileira que regulamenta a distribuicão das compensações financeiras da indústria do petróleo, ver SERRA, R.; GUTMAN, J.; NAZARETH, P.; GOBETTI, S. In: PIQUET, R. (Org.). Mar de Riqueza, Terras de Contrastes: o petróleo no Brasil. Rio de Janeiro: Mauad, 2011. na autonomia dos municípios, que os royalties passam a fazer parte dos instrumentos de recursos que a União aceita dividir entre os integrantes da federação. Portanto, não existem fundamentos teóricos ou jurídicos inquestionáveis que garantam as atuais regras de repasse ${ }^{6}$.

Sem dúvida a região Norte Fluminense mudou com o petróleo. Positivamente no volume do PIB; na morfologia do tecido empresarial; na oferta de postos de trabalho e, principalmente, no aumento dos orçamentos municipais em função dos generosos repasses que o petróleo garante. Simultaneamente, o desafio da abundância permanece presen- 
te, pois caso os critérios de distribuição dos royalties e das participações especiais venham a sofrer mudanças, e há ventos soprando nessa direção, os municípios cujas dinâmicas têm como base tais recursos, enfrentarão sérias restrições orçamentárias.

\section{PARA ALÉM DA MERA DISPUTA POR RECURSOS FINANCEIROS}

Com as descobertas das reservas nas camadas pré-sal o horizonte quanto à importância do petróleo na economia norte fluminense se alongou. Tal fato impõe desde já maior rigor quanto ao uso dos milionários recursos financeiros que terão como base essas novas descobertas. Uma política pública regional responsável deveria buscar identificar oportunidades e alternativas para que a região não permaneça tão dependente da economia petrolífera tendo em vista que hoje dispóe de infraestrutura física, empresas qualificadas, universidades e escolas técnicas, o que configura a existência de externalidades positivas para qualquer empresa industrial. Em que pesem os esforços de alguns municípios em implantar políticas de desenvolvimento local dignas desse nome, o que predomina é o uso predatório do dinheiro público. Segundo dados de pesquisa (CRUZ, 2007), no maior município da região - Campos dos Goytacazes - o Fundo de Desenvolvimento de Campos (Fundecam) possuía, ao final de 2007, recursos aprovados para mais de 60 projetos, dos quais apenas cerca de 10 encontravam-se implantados e 07 em funcionamento regular. Dos 5.500 empregos anunciados na página oficial da instituição e na imprensa local, nem 500 haviam sido gerados de fato. Cruz indica ainda que as referências para contato indicadas não eram sedes das empresas beneficiadas ou não existiam e, que apenas 5 empresários se colocaram disponíveis para entrevistas.

Sobre os municípios de orçamentos milionários vem sendo reforçada a hipótese de estarem enfrentando o paradoxal desafio da abundância. Um desafio que se manifesta, dentre outras formas no descompasso entre a capacidade de planejar o gasto e o ritmo crescente das receitas; na preguiça fiscal resultante da lógica tributária de não incomodar o contribuinte eleitor na medida em que as compensações petrolíferas cobrem as necessidades de gasto das prefeituras; na constituição de cidades "sem crítica", devido ao poder amplo de cooptar os organismos políticos da sociedade civil.

Por ser a legislação brasileira referente à distribuição dos royalties extremamente generosa com os municípios que abrigam empreendimentos do setor e até mesmo com aqueles que são apenas confrontantes com jazidas localizadas na plataforma continental marítima os cofres públicos desses municípios nada têm a reclamar, pelo contrário, têm a agradecer. Se as administraçôes públicas locais aplicam de modo inadequado esses fartos recursos que lhes são repassados, sem que representem melhorias para a população e sem um efetivo controle quanto ao meio ambiente, estas são questôes não específicas ao setor petrolífero ou às empresas que nele operam. São questôes que terão que ser enfrentadas por meio de demandas e exigências diretamente dirigidas às administrações municipais.

No novo cenário que se avizinha - em que o País passará à condição de grande produtor e exportador de petróleo e gás - quando o setor petrolífero assumirá um novo patamar produtivo, antigas e novas questôes serão postas. Dentre elas importa salientar que a exploração e produção dos recursos do pré-sal irá requerer o enfrentamento de significativos desafios tais como: o domínio de tecnologias de ponta capazes de extrair petróleo e gás em profundidades que ultrapassam $7.000 \mathrm{~m}$, com minimização de riscos 
7 Celso Furtado, em estudo pioneiro sobre a Venezuela, de 1957, inicia seu relatório afirmando: "A Venezuela é a economia subdesenvolvida de mais alto nível de produto per capita que existe atualmente no mundo". Afirma ainda ser o país rico em divisas obtidas na exploração de amplas reservas de petróleo, mas, apesar disso, subdesenvolvido.

Rosélia Périssé da Silva Piquet é economista; doutora em Economia; coordenadora do Mestrado em Planejamento Regional e Gestão de Cidades da Universidade Candido Mendes/ Campos; pesquisadora do CNPq. E-mail: ropiquet@terra.com.br

Artigo recebido em março de 2012 e aprovado para publicação em julho de 2012. ambientais; os recursos financeiros que serão exigidos; os custos dessa produção e ainda, o preço mínimo necessário para viabilizar tal produção.

Mesmo diante desse cenário que sinaliza grandes mudanças estruturais na economia brasileira, em 2011 os acalorados debates sobre o novo marco regulatório referente à distribuição dos royalties e das participações especiais dominaram o cenário político e econômico nacional, notadamente dos estados ditos "produtores". As disputas pelas bilionárias rendas têm ofuscado o mais importante atributo da indústria petrolífera brasileira da atualidade, qual seja: as descobertas das ricas jazidas de óleo e gás na camada pré-sal que abrem ao País a possibilidade de garantir às novas gerações brasileiras a oportunidade da oferta de milhares de postos de trabalho, o aumento da renda, o fortalecimento da pesquisa nacional autônoma no setor energético, bem como o fortalecimento do capital local com a formação de novas empresas.

As promissoras perspectivas indicadas podem não se concretizar, pois como afirma Celso Furtado, "o desenvolvimento não é uma fatalidade". Para que isso ocorra, basta que os recursos advindos dessa riqueza sejam aplicados de maneira leviana por nossos dirigentes, tendo como parceiros o desconhecimento e a indiferença da maioria da população brasileira sobre tema de tal relevância nacional.

\section{REFERÊNCIAS BIBLIOGRÁFICAS}

CAETANO FILHO, E. "O papel da pesquisa nacional na exploração e explotação petrolífera da margem continental na Bacia de Campos”. In: PIQUET, R. (Org.). Petróleo, Royalties e Região. Rio de Janeiro: Garamond, 2003. p. 39-94.

CRUZ, J. L. V. Relatório de Pesquisa. Análise e Avaliação sobre o Fundo de Desenvolvimento de Campos dos Goytacazes. Campos dos Goytacazes: 2007. Circulação restrita.

PETROBRAS. Pré-Sal. Essa História Está Só Começando. Disponível em: <http:// www.petrobras.com.br/minisite/presal>. Acesso em: 7 jun. 2011.

PINTO J.; QUEIROZ, H. et al. Economia da energia: fundamentos econômicos, evolução histórica e organização industrial. Rio de Janeiro: Elsevier, 2007. 343p.

PIQUET, R. "Indústria do petróleo e dinâmica regional: reflexões teórico-metodológicas". In: PIQUET, R.; SERRA, R. (Orgs.). Petróleo e Região no Brasil: o desafio da abundância. Rio de Janeiro: Garamond, 2007. p. 15-34.

PIQUET, R. Mar de Riqueza, Terras de Contrastes: o petróleo no Brasil. (Org.). Rio de Janeiro: Mauad/Faperj, 2011. 224p.

PUGA, F.; BORÇA JÚNIOR., G. Perspectiva de investimentos na indústria 20112014. Visão do Desenvolvimento, BNDES, n. 91, fev. 2011. Disponível em: <http:// www.bndes.gov.br/SiteBNDES/bndes/bndes_pt/Institucional/Publicacoes/Consulta_ Expressa/Tipo/Visao_do_Desenvolvimento>. Acesso em: 10 maio 2011.

RAPPEL, E. "A exploração econômica do pré-sal e os impactos sobre a indústria brasileira de petróleo". In: PIQUET, R. (Org.). Mar de Riqueza, Terras de Contrastes: o Petróleo no Brasil. Rio de Janeiro: Mauad, 2011. p. 49-78.

SANT'ANNA, A. A. Brasil é a principal fronteira de expansão do petróleo no mundo. Visão do Desenvolvimento, BNDES, n. 87, out. 2010. Disponível em: <http:// www.bndes.gov.br/SiteBNDES/bndes/bndes_pt/Institucional/Publicacoes/Consulta_ Expressa/Tipo/Visao_do_Desenvolvimento>. Acesso em: 11 maio 2011.

SERRA, R. "O novo marco regulatório do setor petrolífero brasileiro: dádiva ou 
maldição?" In: PIQUET, R. (Org.). Mar de Riqueza, Terras de Contrastes: o Petróleo no Brasil. Rio de Janeiro: Mauad, 2011. p. 141-160.

A B S T R A C T This text aims to discuss a weighty issue of the current energy debate: having rich reserves of oil and gas would be a blessing for a country or the hefty revenues of the exploration of these resources would produce some kind of "curse" by limiting the expansion of other productive sectors? The evaluation of the impacts of this industry is complex for existing deep differences between the changing processes that they can be able to cause in a national level or in the areas they are located in. The text is focused in the phases of exploration and production, in which occur the major investments and are noticed the most significant multiplying effects of this industry, having the Brazilian case as reference. As Brazil has the peculiarity of having the main occurrences in the offshore continental platform, with stressed concentration of the production in Campos Bay, the regional impacts of the industry are analyzed having the case of the North of Rio de Janeiro State as an empirical database of reference.

K E Y W O R D S Oil Industry; oil investments; regional impacts; North of Rio de Janeiro State; multiplying effects. 